\title{
Scintigraphic Pattern in Meckel's diverticulum - a Pictorial Cascade Analysis
}

\author{
Sadia Salam ${ }^{1}$, Simoon Salekin ${ }^{1}$, Mostofa Shamim Ahsan ${ }^{1}$, Nafees Fahmi Ali ${ }^{2}$, Jasmine Ara Haque and Sadia Sultana \\ National Institute of Nuclear Medicine \& Allied Sciences, BSMMU, Bangladesh Atomic Energy Commission. \\ 2 \\ St Helens \&Knowsley Teaching Hospitals, NHS Trust, UK.
}

Address of Correspondence: Dr. Sadia Salam, Assistant Professor, NINMAS, BSMMU Campus, Shahbagh, Dhaka-1000. E-mail: dr.sadiasalam@gmail.com.

\begin{abstract}
Objectives: Meckel's diverticulum, the most common congenital malformation in paediatric patients, usually presents with gastrointestinal bleeding. Nuclear medicine scintigraphy can detect heterotrophic gastric mucosa in Meckel's diverticula. The aim of these case studies was to highlight the different scintigraphic patterns and presentations of Technetium (Tc) 99m pertechnetate scintigraphy of paediatric patients with gastrointestinal (GI) bleeding due to Meckel's diverticulum with a view towards providing guidance in interpretation of variable positive results.

Case Reports: A retrospective image analysis was performed in 6 positive and complicated cases of Meckel's diverticuli between January 2016 and October 2018.

Conclusion: Diverse scan findings were observed. Apart from the usual anatomical location, few other areas like umbilical and paraumbilical regions were found to contain ectopic gastric mucosa. So, these regions should be observed meticulously while reporting.

Bangladesh J. Nucl. Med. Vol. 22 No. 1 January 2019

Doi : https://doi.org/10.3329/bjnm.v22i1.40514
\end{abstract}

\section{INTRODUCTION}

Meckel's diverticulum is the most common congenital malformation of the gastrointestinal tract (incidence 0.6 $4 \%)$ (1). It commonly manifests as gastrointestinal bleeding in paediatric patients. Although several imaging modalities are available, the diagnosis of Meckel's diverticulum prior to surgery remains challenging $(2,3,4,5,6,7,8)$. Nuclear medicine radio scintigraphy can detect heterotrophic gastric mucosa in Meckel's diverticula. The aim of this study was to highlight the different scintigraphic patterns and presentations of Technetium (Tc) $99 \mathrm{~m}$ pertechnetate scintigraphy of paediatric patients with gastrointestinal (GI) bleeding due to Meckel's diverticulum with a view towards providing guidance in interpretation of variable positive results. In order to do this we shall pictorially review six positive scans performed for suspected Meckel's diverticuli in last two years at the National Institute of Nuclear Medicine and Ultrasound, Dhaka, Bangladesh.

\section{CASE REPORTS}

A retrospective image analysis was performed among the 6 positive cases of Meckel's diverticuli with complications between January 2016 and October 2018. Patients were reviewed in view of presenting symptoms, bleeding characteristics, diagnostic studies and pathological diagnosis (if available). $3 \mathrm{mCi}$ Tc- $99 \mathrm{~m}$ pertechnetate was administered intravenously and dynamic flow images were taken anteriorly for 1 minute. Static images were taken at5 minute intervals for 30 minutes followed by delayed imaging at 2 hours.

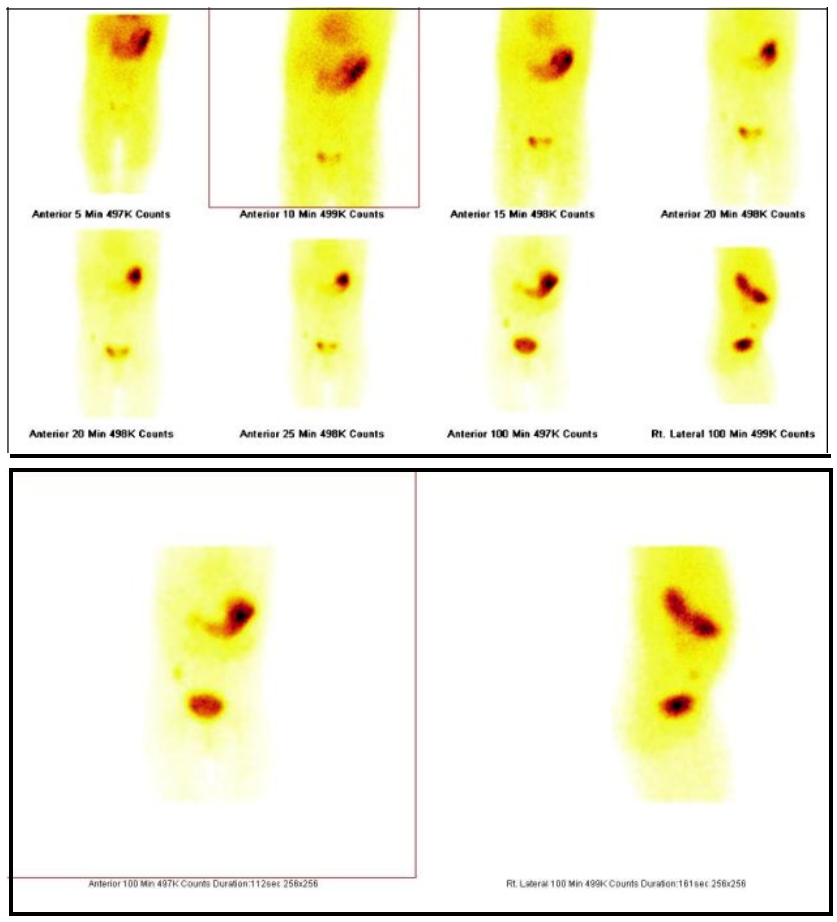

Case1. A 3-year-old girl presented with bleeding per rectum. The scan demonstrated a focal area of increased radiotracer concentration in right lower abdomen at the time of visualization of stomach ( 5 min post injection images) that persisted up to delayed images (1.5 hours), atypical finding for Meckel's diverticulum. 


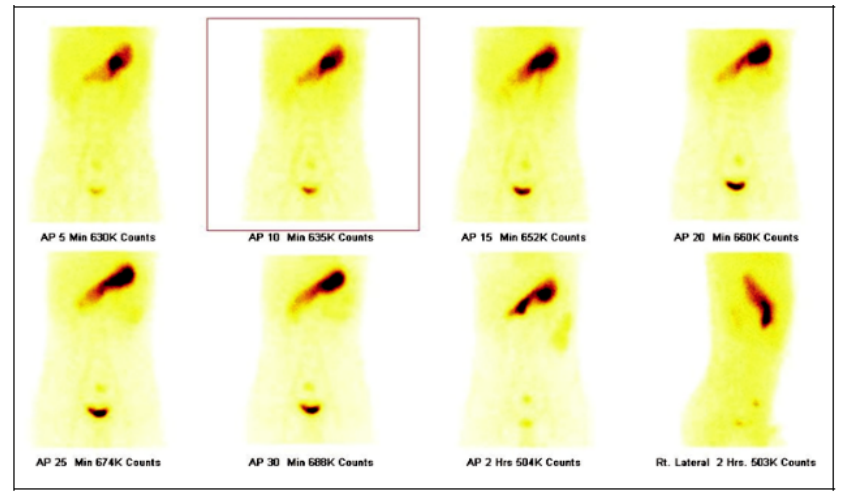

Case 2. A 10 year-old-boy presented with per rectal bleeding for 15/7. Focal area of increased radiotracer concentration in the umbilical region at both early and delayed images is highly suspicious for heterotropic gastric mucosa. Radiotracer activity in the pelvis ; suggests bladder activity.
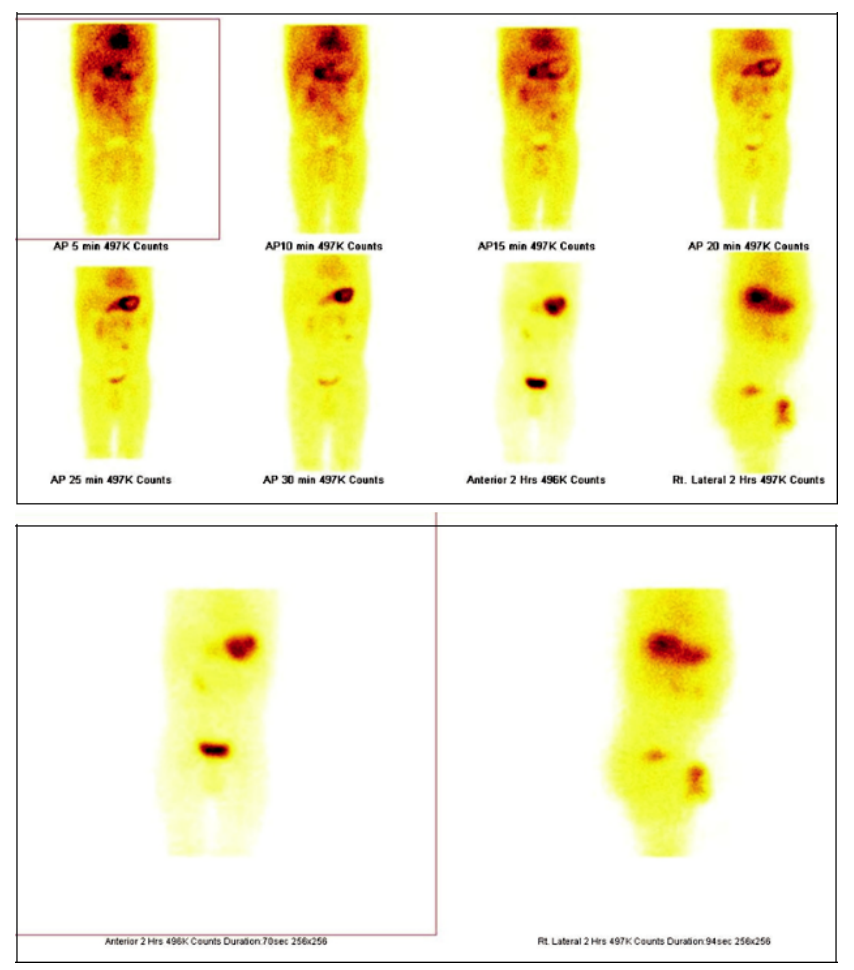

Case 3. A 1 year 8 month old boy presented with one episode of haematochezia 20 days prior the scan associated with occasional malaena. There was a clinical suspicion of portal hypertension. Early image showed two focal areas of increased radiotracer concentration in the right upper abdomen and left paraumbilical region which might be confused with left ureter uptake. However, in the delayed image only the latter persists that suggests presence of Meckel's diverticulum .

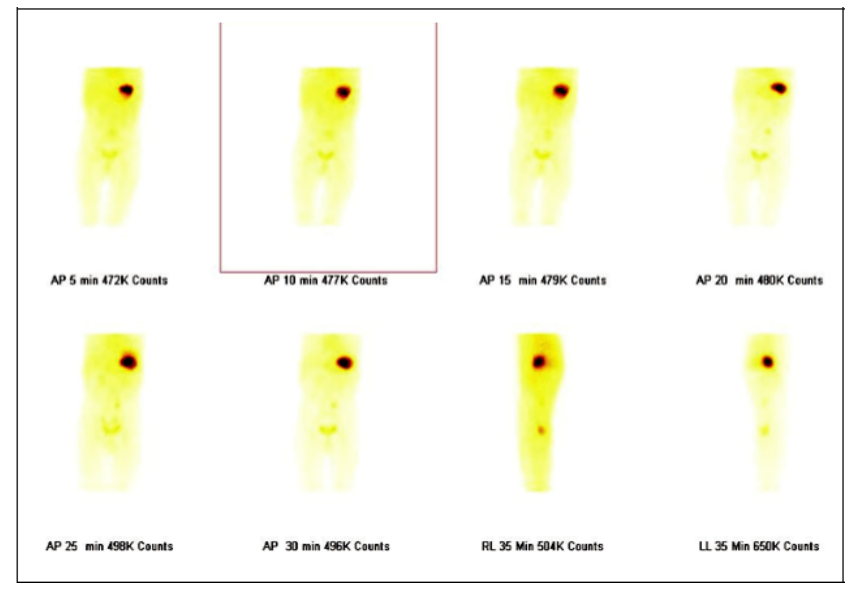

Case 4. A 2 years and 3 months old girl was suffering from both haematochezia and malaena and was undiagnosed for an year. Upper GI endoscopy and colonoscopy were negative. Meckel's scan showed focal increased radiotracer concentration in the left paraumbilical region.

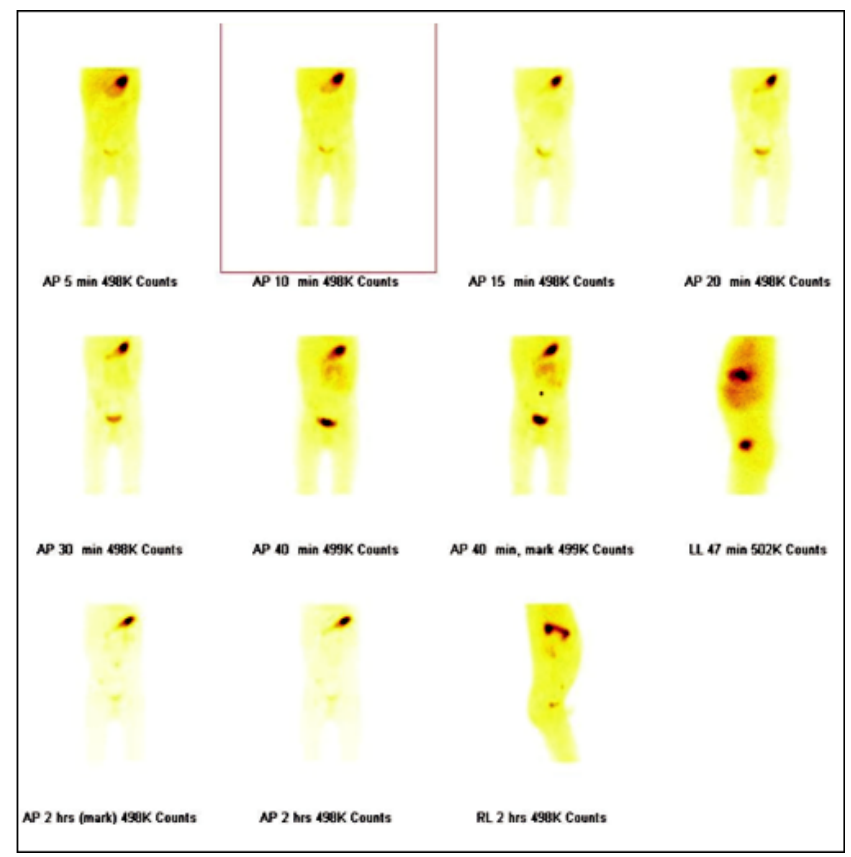

Case 5. A 3 years old boy presented with abdominal pain and vomiting for $3 / 7$. The clinical suspicion and sonographic findings were in favour of intestinal obstruction. However, the planar images showed increased radiotracer concentration in the right iliac fossa in the early images which is highly suggestive of presence of Meckel's diverticulum. Intestinal obstruction is one of the common complications of Meckle's diverticulum. 


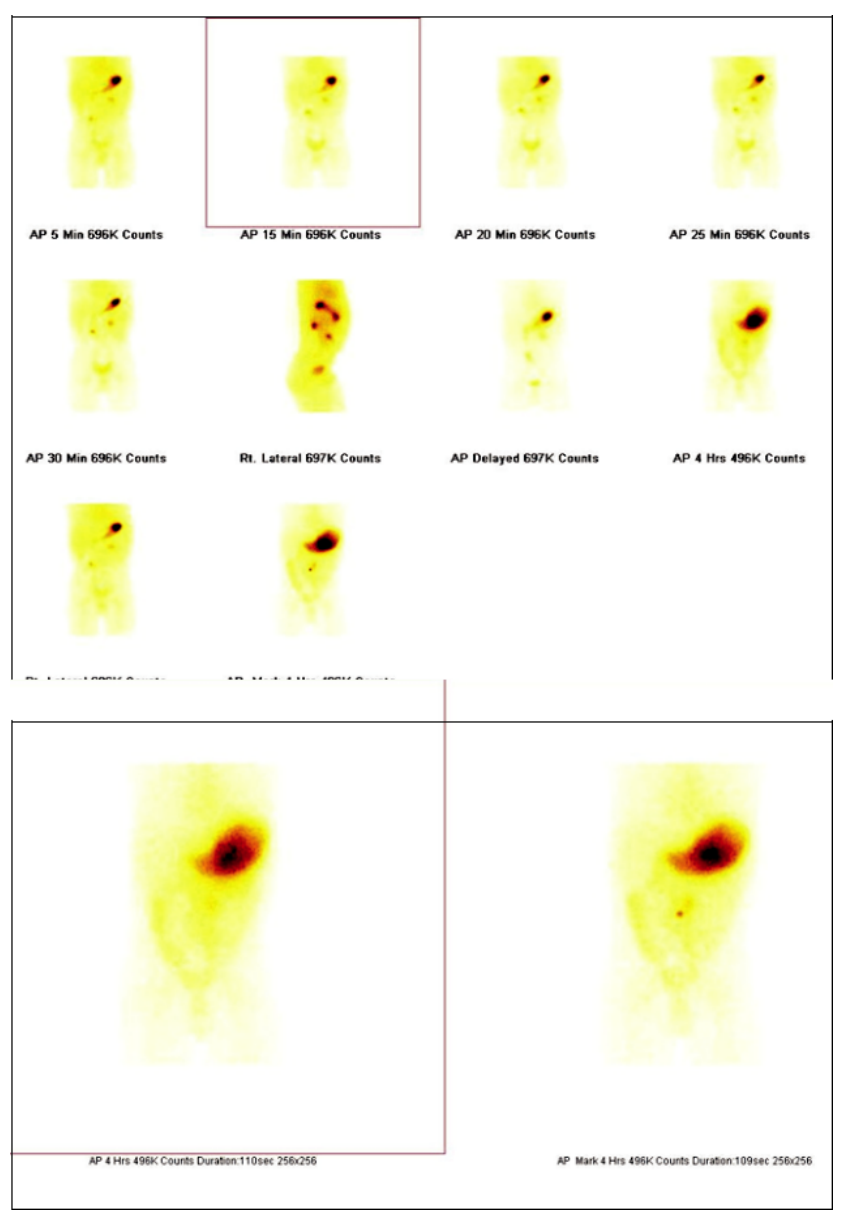

Case 6. A 3 years and 6 months old boy presented with per rectal bleeding for 2 days. Two focal areas of radio tracer uptake were noted in right lower abdomen and left upper abdomen below the stomach and both persisted in the later images. The former represents Meckel's diverticulum and the latter presents ectopic gastric mucosa.

\section{DISCUSSION}

Meckel's diverticulum was originally described by Fabricius Hildanus in 1598. However, it is named after Johann Friedrich Meckel, who established its embryonic origin in 1809 (1). Though Meckel's scintigraphy has been available for decades but it is not widely practiced. The incidence of Meckel's diverticula is low and as a result incidence of positive cases is simultaneously low. It has always been very difficult to diagnose Meckel's diverticula though various type of imaging techniques such as ultrasound, computed tomography, magnetic resonance imaging or Barium meal follow through radiography, with each technique having its own limitations $(9,10,11)$. Planar scintigraphy using Technetium- $99 \mathrm{~m}$ pertechnetate is not widely available in our country but can ensure the presence of Meckel's diverticulum.

The expected typical finding is a focal area of increased radiotracer concentration in right lower abdomen at the time of visualization of stomach that can persist up to the delayed images as demonstrated in Case 1. However, it is not uncommon to find focal radiotracer concentration in umbilical or para-umbilical regions as evident in case 2,3

\& 4. Focal radiotracer concentration can be present in the left para-umbilical region as well as in mid abdomen which can raise suspicions of ectopic gastric or pancreatic mucosa. However, the disappearance of these in the delayed images proves that this is most likely to be normal stomach/duodenal activity.

Intestinal obstruction is a common complication of Meckel's diverticula (12). Case 5 was clinically and sonographically diagnosed as intestinal obstruction and Meckel's scan was found to be positive.

Case 6 revealed Two focal area of radio tracer concentration, one in right lower abdomen and other in left mid abdomen below stomach, which was suspicious for left renal or ureteric uptake. Horseshoe kidneys, caliceal diverticulum and urinary tract obstruction $r$ may cause false-positive scans. However, both uptakes were persistent in the delayed images, the former being a Meckel's diverticulum and the latter was found to be ectopic gastric mucosa .

Avoidance of administration of few drugs like pentagastrin, cimetidine and glucagon and certain procedures prior to 48 hours, such as administration of cathartics (drugs that irritate the gastrointestinal tract), contrast-enhanced studies, endoscopy, and use of enemas enhance the quality of scan.

\section{CONCLUSION}

Meckel's scan with Tc-99m pertechnetate is simple, non invasive but useful technique to diagnose Meckel's diverticulum prior surgery. However, the scan findings 
show diversity. Apart from the usual anatomical location few other areas like umbilical and para-umbilical areas are more prone to findings of ectopic gastric mucosa and these should be observed carefully while reporting.

\section{REFERENCES}

1. Sagar J, Kumar V, Shah DK. Meckel's diverticulum: a systematic review.Journal of the Royal Society of Medicine.

2006;99(10):501-505. doi:10.1258/jrsm.99.10.501

2. Hol L, KuipersEJ.Clinical challenges and images in GI.Mekel's diverticulum. Gastroenterology.2007 Aug.133 (2):392, 732.doi:10.1053/j.gastro.2007.06.050

3. Emamian SA; Shalaby-Rana E; Majd M. The spectrum of heterotopic gastric mucosa in children detected by Tc-99m pertechnetate. ClinNucl Med. 2001; 26(6):529-35

4. Linebarger JS; Roy ML.Focus on diagnosis: common nuclear medicine studies in pediatrics. Pediatr Rev. 2007; 28(11):415-7 (ISSN: 1526-3347)

5. DelleChiaie L; Neuberger P. Early prenatal sonographic detection of an uncomplicated Meckeldiverticulum. Ultrasound Obstet Gynecol. 2007; 30(5):790-1 (ISSN: 0960-7692) doi: 10.1258/jrsm.99.10.501
6. Nolan DJ.The true yield of the small-intestinal barium study.Endoscopy. 1997; 29(6):447-53 (ISSN: 0013-726X)

7. Omar AM; Al-Saee'd TA; Elgazzar A. Scintigraphic pattern of intestinal duplication on a Meckel's diverticulum scan.ClinNucl Med. 1998; 23(10):708-9 (ISSN: 03639762)

8. Swaniker F; Soldes O; Hirschl RB. The utility of technetium $99 \mathrm{~m}$ pertechnetatescintigraphy in the evaluation of patients with Meckel's diverticulum. J Pediatr Surg. 1999; 34(5):7604; discussion 765 (ISSN: 0022-3468)

9. Sancar S, Demirci H, Sayan A, et al. Meckel's diverticulum: ten years' experience. UlusCerrahi Derg2015;31:65-7.https://doi.org/10.1159/000493439

10. Rattan KN, Singh J, Dalal P, et al. Meckel's diverticulum in children: our 12-year experience. Afr J PaediatrSurg 2016;13:170-4. doi: 10.1097/MD.0000000000007760

11. Papparella A, Nino F, Noviello C, et al. Laparoscopic approach to Meckel's diverticulum. World J Gastroenterol 2014;20:8173-8.doi: 10.3748/wjg.v20.i25.8173

12. Lin XK, Huang XZ, Bao XZ, Zheng N, Xia QZ, Chen CD. Clinical characteristics of Meckel diverticulum in children: A retrospective review of a 15-year single-center experience. Medicine (Baltimore). 2017;96(32):e7760. doi: 10.1097/MD.0000000000007760 